\title{
Perbedaan Metode Transplantasi Terhadap Laju Pertumbuhan Acropora aspera Pada Artificial Patch Reef Di Pulau Panjang, Jepara
}

\author{
Bintang Prayoga*, Munasik, Irwani \\ Departemen IImu Kelautan, Fakultas Perikanan dan IImu Kelautan, Universitas Diponegoro \\ JI.Prof.H.Soedarto S.H, Tembalang,Semarang, Jawa Tengah 50275 Indonesia \\ ${ }^{*}$ Corresponding author, e-mail: bintangprayoga9@gmail.com
}

\begin{abstract}
ABSTRAK: Artificial Patch Reef (APR) adalah salah satu terumbu karang buatan yang dirancang dengan bentuk melingkar modular berbentuk piramida dan memiliki 4 tingkatan atau kedalaman yang berbeda. Penelitian ini menggunakan Acropora aspera sebagai karang yang akan ditransplan pada APR karena saat ini populasi dari Acropora sangat terdegradasi dan terus menurun. Penelitian dilaksanakan pada bulan April hingga Juli 2018 di perairan Pulau Panjang Jepara. Penelitian bertujuan untuk mengetahui laju pertumbuhan Acropora aspera dengan variasi metode yaitu ditransplan secara vertikal dan horizontal. Kedua metode memiliki keuntungan masingmasing dengan metode vertikal memiliki peluang pertumbuhan yang lebih cepat karena pertumbuhan pada karang selalu menuju ke arah datangnya sinar matahari, keuntungan dari posisi penanaman secara horizontal adalah posisi yang optimal karena hasilnya karang tetap dapat tumbuh pada dua sisi dan dapat tumbuh ke segala arah. Selain itu penelitian ini menggunakan 3 kedalaman yang berbeda. Pertumbuhan tertinggi pada perbedaan metode terjadi pada metode vertikal dengan laju pertumbuhan sebesar $0,35 \mathrm{~cm} /$ bulan sedangkan pada metode horizontal didapat hasil sebesar $0,27 \mathrm{~cm} /$ bulan. Untuk laju pertumbuhan pada perbedaan kedalaman atau tingkatan didapatkan laju pertumbuhan untuk tingkat 2 sebesar $0,24 \mathrm{~cm} / \mathrm{bulan}$, tingkat 3 sebesar $0,34 \mathrm{~cm} /$ bulan dan tingkat 4 sebesar $0,35 \mathrm{~cm} /$ bulan. Analisis statistik ANOVA menunjukkan pada tingkatan dan metode diperoleh nilai Sig. 0,00 yang berarti $\mathrm{H} 1$ diterima, berarti ada perbedaan signifikan antar metode dan antar tingkatan.
\end{abstract}

Kata kunci: Transplantasi; Acropora aspera; Artificial Patch Reef; Pulau Panjang Jepara

\section{Differences in the Transplant Method Against the Aspera acropora Growth Rate on Artificial Patch Reef in Panjang Island, Jepara}

\begin{abstract}
Artificial Patch Reef (APR) is one of the artificial reefs that is designed with a circular pyramidal modular shape and has 4 different gradations or depths. This study used Acropora aspera as the coral to be transplanted in the APR because currently the population of Acropora is highly degraded and continues to decrease. This research was conducted from April to July 2018 on the Panjang Island, Jepara. This research use Acropora aspera with a variety of methods that transplanted vertically and horizontally. Both methods have advantages. Vertical method has chance to growth faster than horizontal method. In the direction that comes from sunlight, the benefits of planting horizontally are optimal because they produce corals that can grow on both sides and can grow to all direction. In addition, this study uses 3 different levels. The highest method obtained in the vertical method with a growth rate of $0.35 \mathrm{~cm} /$ month in the horizontal method results obtained at $0.27 \mathrm{~cm} /$ month. For the growth rate at the growth rate or growth rate for level 2 of $0.24 \mathrm{~cm} /$ month, level 3 is $0.34 \mathrm{~cm} /$ month and level 4 is $0.35 \mathrm{~cm} /$ month. Statistical analysis of ANOVA determines at the level and method obtains the Sig. 0,00 which means H1 is accepted, meaning there are significant differences between methods and between levels.
\end{abstract}

Keywords: Transplantion; Acropora aspera; Artificial Patch Reef; Panjang Island Jepara 


\section{PENDAHULUAN}

Pulau Panjang merupakan kawasan perairan laut di utara Kota Jepara yang secara geografis berada kurang lebih 1 mil dari Pantai Kartini dengan posisi koordinat bumi antara 6o34'30" LS dan 110037'45" BT. Pulau Panjang merupakan daratan dengan luas 25.000 m2 yang dikelilingi oleh padang lamun dan ekosistem terumbu karang

Perlu dilakukan usaha dalam menjaga kelestarian terumbu karang agar tidak semakin memburuk kondisinya (Suharsono, 2008). Area terumbu karang yang telah rusak pada dasarnya memiliki kemampuan untuk pulih secara alami tetapi membutuhkan waktu yang cukup lama untuk memulihkan area hingga kembali menjadi baik kembali (Hermanto, 2015). Teknologi transplantasi karang adalah salah satu alternatif upaya untuk pemulihan terumbu karang melalui pemotongan karang hidup untuk ditransplan di tempat lain atau di tempat yang karangnya telah mengalami kerusakan, bertujuan untuk pemulihan terumbu karang alami di lokasi transplantasi karang (Yunus et al., 2013).

Terumbu karang buatan (artificial reefs) biasa terbuat dari berbagai macam konstruksi dan material. Berbagai macam konstruksi dan material yang biasa digunakan dalam pembuatan artificial reefs dilakukan dengan meniru beberapa karakteristik terumbu karang alami sehingga dapat memikat jenis-jenis organisme laut untuk hidup dan menetap (Pardede, 2012).

Artificial Patch Reef (APR) adalah terumbu karang buatan yang akan digunakan pada penelitian ini. APR adalah salah satu terumbu karang buatan yang dirancang dengan bentuk melingkar modular berbentuk piramida dan memiliki 4 tingkatan atau kedalaman yang berbeda, dikerahkan dari perahu-perahu kecil yang membawa muatan dan diletakkan oleh penyelam, terumbu karang buatan ini sangat cocok di letakan dekat terumbu karang alami untuk perairan dangkal dengan jarak pandang Pulau Panjang yang rendah. (Munasik et al., 2017).

Penelitian ini menggunakan Acropora aspera sebagai karang yang akan ditransplan pada karang buatan karena menurut Lirman et al., (2012) saat ini populasi dari Acropora sangat terdegradasi, terus menurun, dan mungkin tidak akan pulih tanpa adanya campur tangan manusia.

Tujuan dari penelitian ini adalah untuk mengetahui perbandingan antara metode transplantasi vertikal dan horizontal pada APR dengan mengamati laju pertumbuhan karang Acropora aspera yang ditranplantasi pada APR. Perbedaan dari kedua metode ini adalah karang yang ditransplantasikan secara vertikal memiliki peluang pertumbuhan yang lebih cepat karena pertumbuhan pada karang selalu menuju ke arah datangnya sinar matahari (Soedharma dan Arafat, 2005).

Laju pertumbuhan karang transplan pada 3 tingkatan atau kedalaman yang berbeda pada APR akan diamati karena menurut Supriharyono (2007), kedalaman juga membatasi kehidupan binatang karang.

\section{MATERI DAN METODE}

Materi yang digunakan dalam penelitian ini adalah Acropora aspera yang diperoleh dari perairan Pulau Panjang, Kabupaten Jepara, Jawa Tengah. Transplantasi karang dilakukan pada Artificial Patch Reef yang sebelumnya telah diletakkan di perairan Pulau Panjang, Jepara.

Metode penelitian ini adalah metode eksperimen lapangan, yaitu suatu cara untuk mengetahui hubungan sebab akibat dengan cara memberikan satu atau lebih perlakuan dan membandingkan hasilnya untuk dilihat pengaruhnya terhadap obyek penelitian yang dilakukan di lapangan (Nazir, 1988). Penelitian ini menggunakan Rancangan Acak Lengkap (RAL) dengan pola $(2 \times 3 \times 10)$. Faktor pertama yaitu metode dengan 2 taraf perlakuan yaitu vertikal dan horizontal. Faktor kedua adalah tingkatan dengan 3 taraf perlakuan yaitu tingkat 2, 3 dan 4 . Perlakuan dalam penelitian ini adalah hasil interaksi antar faktor dari seluruh taraf perlakuan. Dengan demikian dalam penelitian terdapat $2 \times 3$ kombinasi perlakuan yaitu 6 interaksi dengan 10 kali ulangan.

Persiapan awal penelitian adalah dengan pengambilan koloni karang yang dilakukan di Pulau Panjang Jepara dengan menggunakan perahu dan alat snorkeling. Pengambilan koloni karang tidak jauh dari lokasi APR sendiri, pengambilan dilakukan dengan menggunakan tang potong untuk memotong karang branching. Koloni karang yang diambil adalah karang dengan 
genus Acropora. Koloni karang yang dipilih adalah karang berbentuk branching yang memiliki panjang percabangan sekitar $8 \mathrm{~cm}$ dan diameter $1 \mathrm{~cm}$ dengan kondisi karang sehat atau bebas penyakit dan tidak mengalami bleaching (pemutihan karang).

Jumlah koloni yang digunakan adalah 1 koloni dan patahan-patahan karang yang masih hidup. Selanjutnya koloni dan patahan karang dipotong menjadi fragmen berbentuk memanjang sebanyak 60 potong dan dibagi menjadi 2 yaitu sebanyak 30 untuk transplan secara vertikal dan 30 secara horizontal. Kondisi awal sampel dipotong diusahakan mendekati ukuran yang diinginkan yaitu dengan panjang $7-8 \mathrm{~cm}$. Ukuran awal yang digunakan adalah $7-8 \mathrm{~cm}$ karena ukuran tersebut adalah yang biasa digunakan dalam kegiatan transplantasi.

Koloni karang yang telah dipotong dan diambil dari lokasi sampling langsung dibawa ke lokasi penelitian. Selamjutnya, dilakukan aklimatisasi dengan cara disimpan di dalam jaring lalu dikaitkan pada APR yang menjadi tempat penelitian.. Aklimatisasi dilakukan selama 24 jam dengan tujuan agar induk dapat beradaptasi dengan lokasi penelitian yang telah ditentukan sehingga mengurangi resiko terjadinya stress yang berlebihan pada karang saat ditranplantasi nantinya.

\section{Media Transplan}

Media untuk penempelan fragmen karang adalah Artificial Patch Reef (APR) yaitu sebuah media yang dibuat dari balok beton yang disusun berbentuk menyerupai piramida tersusun atas 4 tingkatan dengan tiap 1 tingkatan memiliki jarak sebanyak $30 \mathrm{~cm}$ antar satu tingkatan dengan tingkatan lainnya. Tingkatan yang digunakan nantinya adalah tingkat 2,3 dan 4 dengan masingmasing tingkatan akan diberikan kode berupa huruf $A, B$ dan $C$. Berikut adalah desain penempatan sampel pada Gambar 1

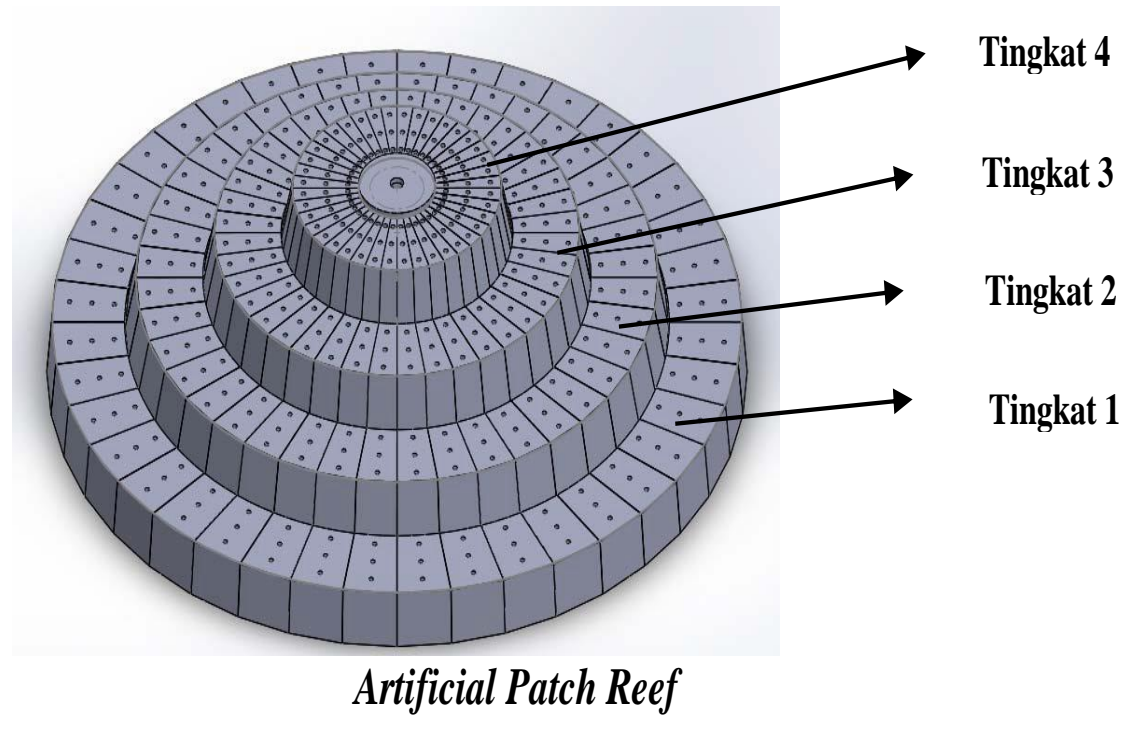

Gambar 1. Gambar Artificial Patch Reef Secara Umum (Munasik et al., 2017)

\section{Transplantasi Karang}

Karang yang telah diaklimatisasi ditransplantasi secara vertikal dan horizontal pada 3 tingkatan yaitu tingkat 2,3 dan 4. Peletakan karang transplan pada APR diatur dengan jarak antar fragmen sekitar $20 \mathrm{~cm}$. Karang transplan yang diletakkan tiap tingkatan masing-masing berjumlah 20 karang masing-masing sebanyak 10 karang ditransplan secara vertikal dan 10 karang ditransplan secara horizontal sebanyak 3 tingkatan. 


\section{Pengumpulan Data}

Pengamatan dilakukan setiap 2 minggu sekali untuk mengtahui apakah ada gangguan yang terjadi seperti badai, pemangsaan dan kompetitor seperti alga (Edward \& Gomez, 2008). Proses pemotongan fragmen meninggalkan bekas luka, sehingga fragmen butuh waktu untuk melakukan proses penutupan luka. Pengamatan pada 2 minggu pertama adalah untuk mengamati tutupan luka akibat fragmentasi karang yang telah dilakukan. Pembersihan sekitar karang dilakukan dengan cara membersihkan sedimen yang berada di sekitar karang transplan agar tidak ditumbuhi alga dengan menggunakan sikat. Dalam kegiatan transplantasi akan dilakukan pemantauan dengan tujuan untuk memeriksa transplan dari gangguan pemangsa dan alga yang menempel pada karang agar dapat dilakukan langkah pencegahan atau pembersihan, bila diperlukan (Edward \& Gomez, 2008).

\section{Analisis Data}

Menurut Effendie (1979) pengukuran pertumbuhan panjang dan diameter karang dapat digunakan rumus, sebagai berikut :

$$
\beta L=L t-L o
$$

Keterangan : $\beta \mathrm{L}$ : Pertumbuhan mutlak tinggi $(\mathrm{cm}), \mathrm{Lt}:$ Rata - rata tinggi setelah bulan $\mathrm{ke}, \mathrm{t}(\mathrm{cm})$ Lo : Rata - rata tinggi pada waktu pengukuran awal $(\mathrm{cm})$.

Selanjutnya untuk pengukuran laju pertumbuhan karang menurut Effendie (1979) dapat dilakukan dengan cara menggunakan rumus, berikut ini :

$$
P=\frac{\mathrm{Lt}-\mathrm{Lot}}{\mathrm{t}}
$$

Keterangan : $\mathrm{P}$ : Capaian pertumbuhan karang (cm bulan-1), Lt : Rata - rata tinggi setelah diakhir penelitian $(\mathrm{cm})$, Lot : Rata - rata tinggi pada waktu pengukuran awal $(\mathrm{cm}), \mathrm{t}$ : Waktu pengamatan (bulan)

\section{Parameter Lingkungan}

Pengukuran parameter perairan dilakukan pada saat pertama kali dilakukan penelitian. Pengukuran parameter perairan, meliputi: suhu, salinitas, $\mathrm{pH}$ dan kecerahan yang ada di sekitar lokasi penelitian. Pengukuran dilakukan karena parameter perairan adalah faktor-faktor pembatas pada terumbu karang

Sedimentasi merupakan salah satu pembatas pertumbuhan karang, hal ini diakibatkan karena tingginya sedimentasi pada suatu lokasi akan menyebabkan penetrasi cahaya di air laut akan berkurang dan hewan karang (polip) akan bekerja keras untuk membersihkan partikel sedimen yang menutupi tubuhnya. Pengukuran sedimentasi dilakukan untuk mengetahui tingkat sedimentasi pada lokasi penelitian.

\section{HASIL DAN PEMBAHASAN}

Hasil pada penelitian yang telah dilakukan diperoleh hasil bahwa pertumbuhan tertinggi terjadi pada fragmen karang yang ditransplan pada tingkat 4 metode vertikal dengan panjang yang meningkat dari rata-rata ukuran awal $(8,1 \pm 0,36)$ menjadi $(9,75 \pm 0,67)$. Ukuran lainnya pada tingkat 4 dengan metode transplan horizontal meningkat dari $(8,05 \pm 0,12)$ menjadi $(9,22 \pm 0,16)$. Tingkat 3 dengan metode transplan vertikal diperoleh hasil pertumbuhan dengan tinggi awal $(8,17$ $\pm 0,402)$ menjadi $(9,72 \pm 0,81)$ dan pada metode transplan horizontal diperoleh pertumbuhan dari tinggi awal $(8,03 \pm 0,21)$ menjadi $(9,17 \pm 0,173)$. Pada kedalaman terendah yaitu tingkat 2 diperoleh hasil pertumbuhan dengan metode transplan secara vertikal mengalami peningkatan dari $(8,00 \pm 0,21)$ menjadi $(9,05 \pm 0,17)$ dan dengan metode horizontal mengalami peningkatan dari $(7,91 \pm 0,20)$ menjadi $(8,81 \pm 0,19)$. (Gambar 2,3 dan 4) 
Journal of Marine Research Vol.8, No.1 Februari 2019, pp. 1-10

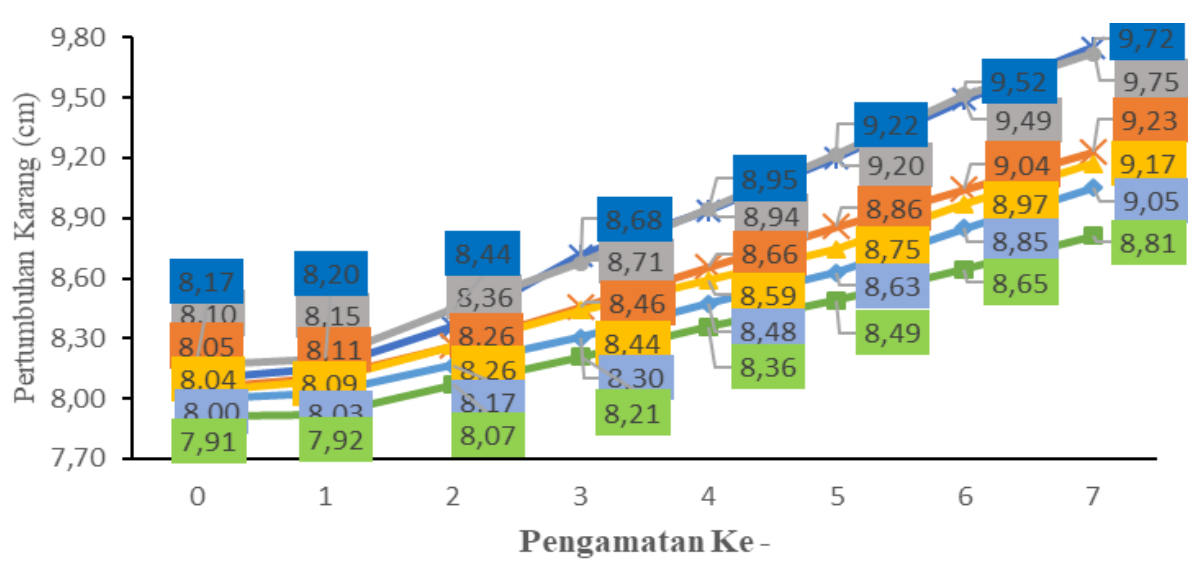

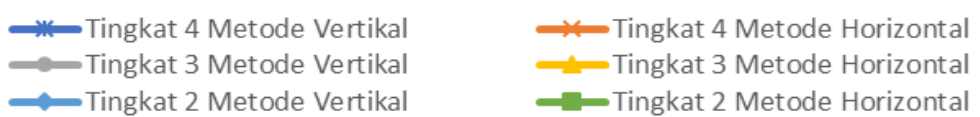

Gambar 2. Grafik Pertumbuhan Karang Transplan 4 Bulan

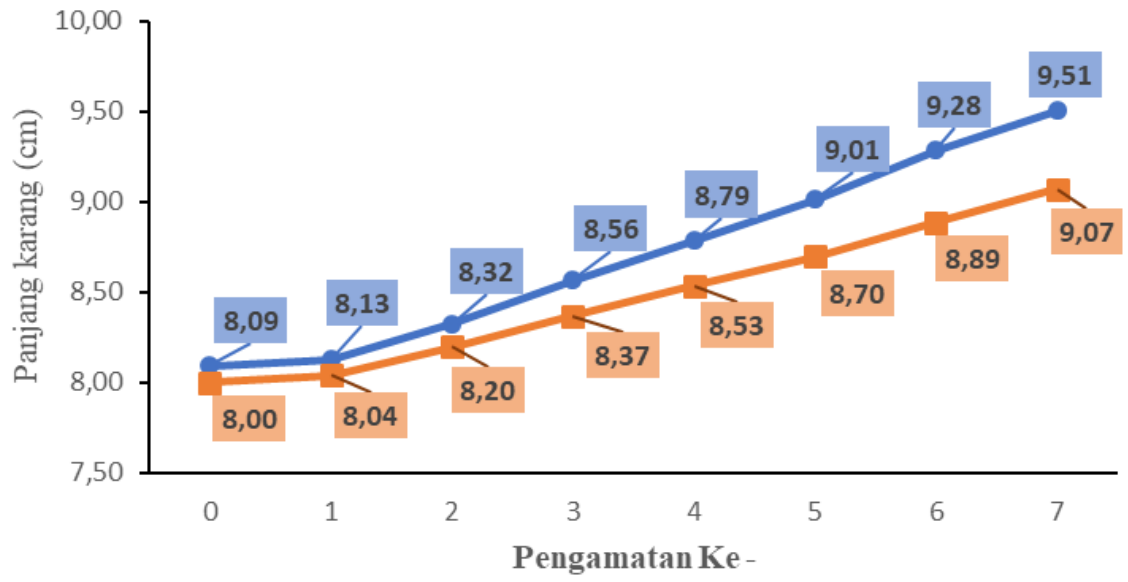

Metode Transplan Vertikal $\quad$ Metode Transplan Horizontal

Gambar 3. Grafik Pertumbuhan Karang 2 Metode Berbeda

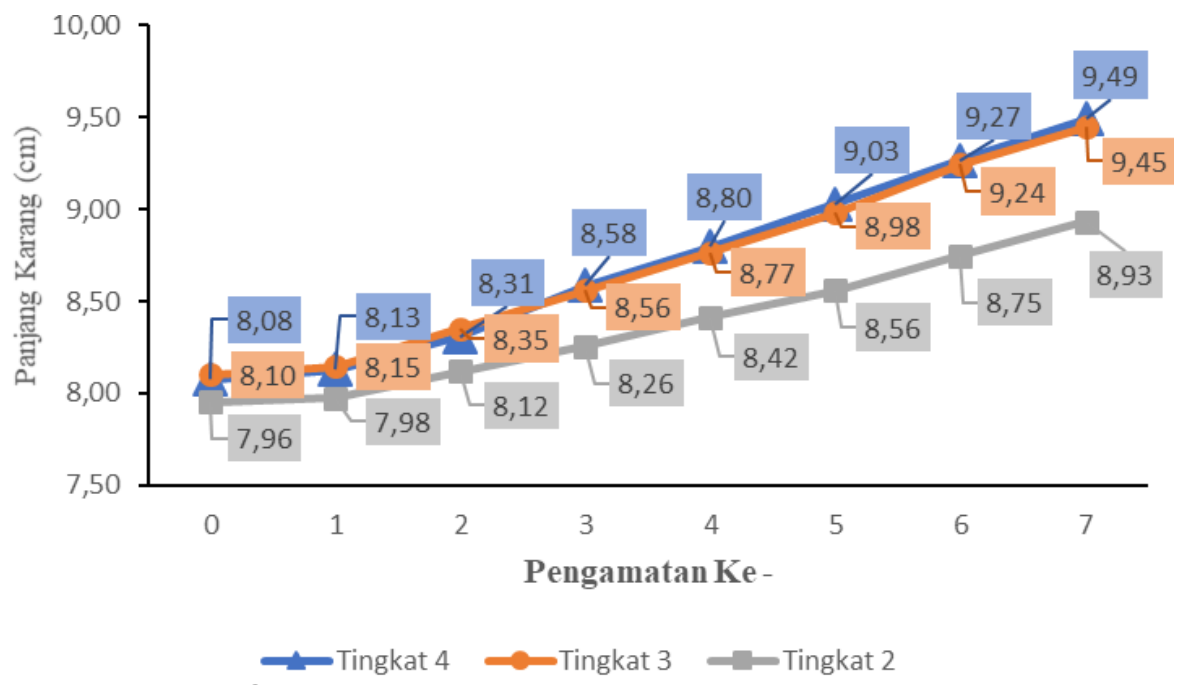

Gambar 4. Grafik Pertumbuhan Karang pada 3 Tingkat Berbeda 
Pertumbuhan karang transplan Acropora aspera pada setiap tingkat dan metode mempunyai pertumbuhan yang positif. Namun semakin rendah tingkat transplan menunjukkan hasil pertumbuhan yang lebih lambat dibandingkan dengan tingkat 4 yang lebih dekat dengan permukaan air. Hasil pertumbuhan juga didapatkan hasil berupa fragmen karang yang ditransplan dengan metode vertikal memiliki pertumbuhan yang lebih baik dibandingkan dengan karangkarang yang ditransplan dengan metode transplan secara horizontal.

laju pertumbuhan karang transplan dengan hasil tertinggi ditemukan pada karang transplan tingkat 4 dengan metode transplan secara vertikal dengan laju pertumbuhan mencapai 0,4125 $\mathrm{cm} /$ bulan. Laju pertumbuhan terendah pada akhir penelitian ditunjukan pada karang transpalan tingkat 2 dengan metode transplan secara horizontal dengan laju pertumbuhan $0,225 \mathrm{~cm} / \mathrm{bulan}$.

Laju pertumbuhan karang transplan lainnya adalah pada tingkat 4 dengan metode transplan horizontal dengan laju pertumbuhan $0,29 \mathrm{~cm} /$ bulan. Pada tingkat 3 didapatkan laju pertumbuhan dengan metode transplan vertikal sebesar $0,38 \mathrm{~cm} /$ bulan dan $0,28 \mathrm{~cm} /$ bulan pada metode transplan horizontal. Dan yang terakhir pada tingkat 2 dengan metode transplan vertikal didapatkan laju pertumbuhan sebesar 0,26 cm/bulan. Dibawah ini dapat dilihat Gambar 5, 6 dan 7 yaitu histogram yang menunjukkan laju pertumbuhan karang transplan.

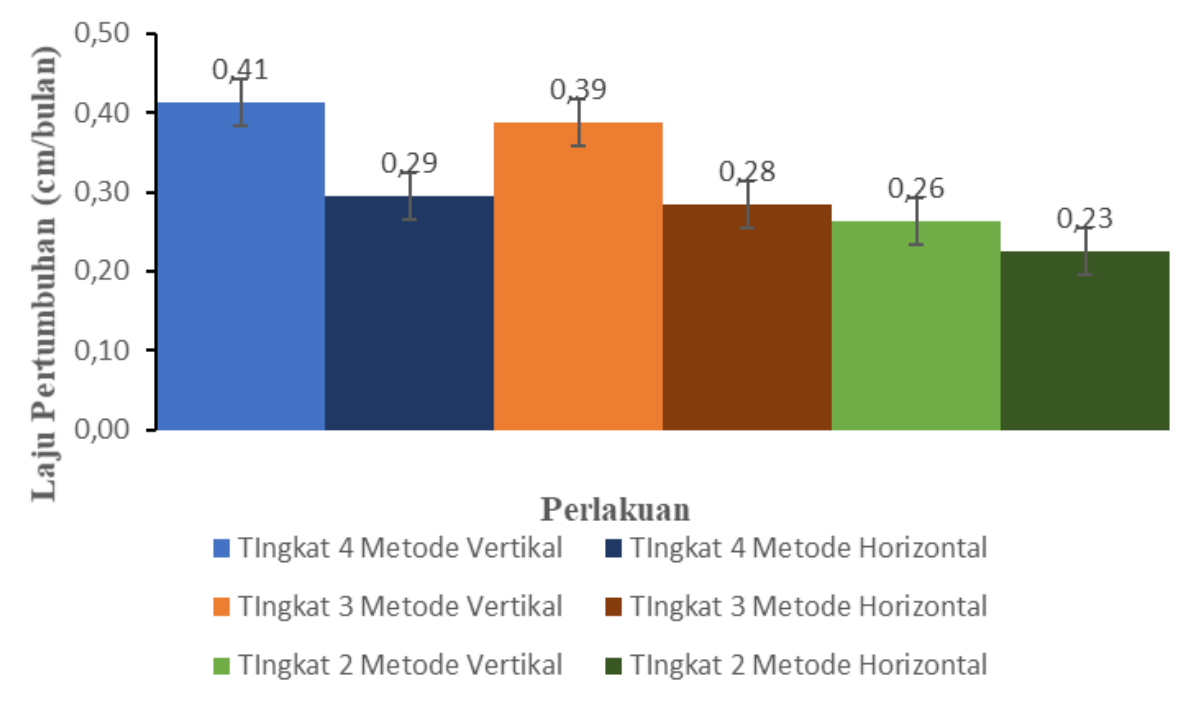

Gambar 5. Histogram Laju Pertumbuhan Karang Transplan 4 Bulan

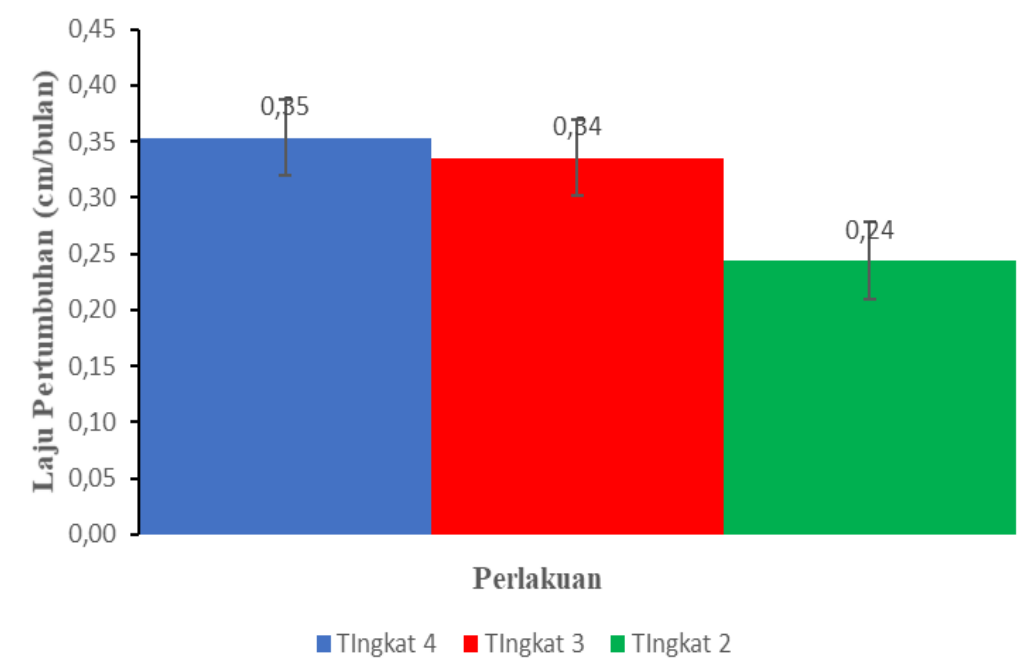

Gambar 6. Histogram Laju Pertumbuhan Berdasarkan Tingkat 


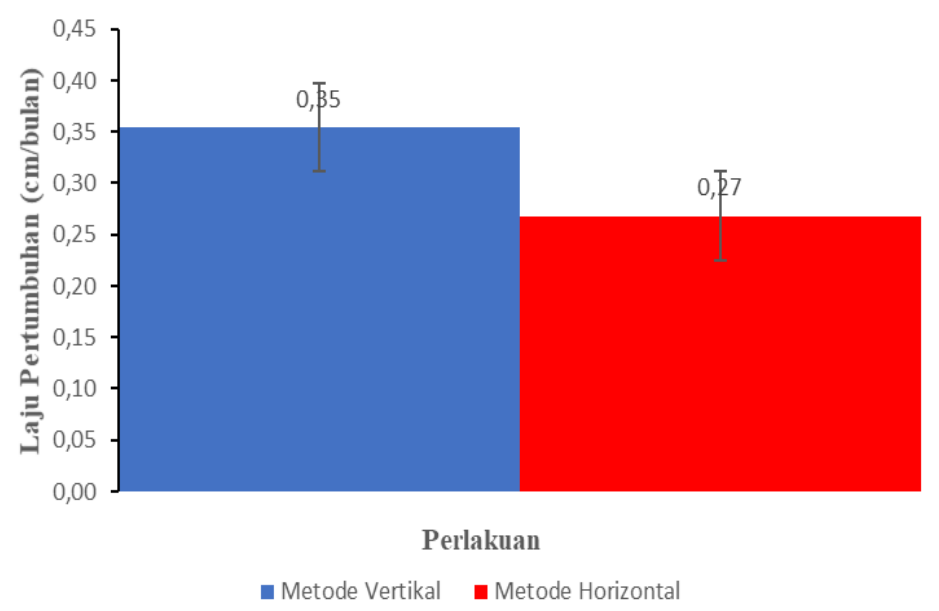

Gambar 7. Histogram Laju Pertumbuhan Berdasarkan Metode

Pada akhir penelitian terlihat bahwa pertumbuhan tertinggi rata-rata terjadi pada fragmen karang dengan metode transplan vertikal dengan rata-rata laju pertumbuhan $0,26-0,45 \mathrm{~cm} / \mathrm{bulan}$, dibandingkan dengan metode transplan secara horizontal yang memiliki laju pertumbuhan 0,22 $0,29 \mathrm{~cm} /$ bulan. Sedangkan pada perbedaan tingkat diperoleh hasil laju pertumbuhan tertinggi ditemukan pada tingkat 4 dengan laju pertumbuhan sebesar $0,35 \mathrm{~cm} / \mathrm{bulan}$, lalu tingkat 3 dengan laju pertumbuhan $0,34 \mathrm{~cm} /$ bulan dan tingkat 2 dengan laju pertumbuhan terendah sebesar 0,24 $\mathrm{cm} /$ bulan.

Berdasarkan hasil uji statistic ANOVA yang telah dilakukan untuk mengetahui pengaruh signifikan perbedaan metode dan tingkat terhadap laju pertumbuhan karang Acropora aspera maka didapatkan hasil berikut:

\begin{tabular}{|c|c|c|c|}
\hline \multicolumn{4}{|c|}{ Between-Subjects Factors } \\
\hline & & Value Label & $\mathrm{N}$ \\
\hline \multirow[t]{3}{*}{ Tingkatan } & 2 & & 20 \\
\hline & 3 & & 20 \\
\hline & 4 & & 20 \\
\hline \multirow[t]{2}{*}{ Metode } & 1 & Vertikal & 30 \\
\hline & 2 & Horizontal & 30 \\
\hline
\end{tabular}

Tests of Between-Subjects Effects
\begin{tabular}{|c|c|c|c|c|c|}
\hline Dependent Variable:Laju & Type III Sum of \\
Squares & df & Mean Square & F & Sig. \\
\hline Corrected Model & $.310^{\mathrm{a}}$ & 5 & .062 & 10.862 & .000 \\
Intercept & 5.527 & 1 & 5.527 & 969.402 & .000 \\
Tingkatan & .162 & 2 & .081 & 14.188 & .000 \\
Metode & .112 & 1 & .112 & 19.610 & .000 \\
Tingkatan * Metode & .036 & 2 & .018 & 3.163 & .051 \\
Error & .308 & 54 & .006 & & \\
Total & 6.144 & 60 & & & \\
Corrected Total & .618 & 59 & & & \\
\hline
\end{tabular}

a. $\mathrm{R}$ Squared $=.501$ (Adjusted R Squared $=.455)$

Gambar 8. Uji ANOVA pengaruh metode dan tingkat terhadap laju pertumbuhan

Berdasarkan hasil yang didapatkan, sebagaimana ditunjukan pada gambar 8 bahwa pada tingkatan dan metode diperoleh nilai Sig. 0,00 yang berarti $\mathrm{H} 1$ diterima, berarti ada perbedaan 
signifikan antar tingkatan dan antar metode. Namun, pada interaksi tingkatan dan metode diperoleh nilai Sig. 0,051 yang berarti $\mathrm{H} 1$ tidak diterima, artinya tidak terdapat perbedaan signifikan. Nilai $F$ hitung tingkatan diperoleh sebesar $14,188 \geq F$ tabel $\alpha=0,05 d f=1,54=3,17$ yang berarti terima $\mathrm{H} 1$, ada perbedaan signifikan antar tingkatan. Nilai $\mathrm{F}$ hitung metode diperoleh sebesar $19,610 \geq \mathrm{F}$ tabel $_{\alpha}=0,05 \mathrm{df}=2,54=4,02$ yang berarti terima $\mathrm{H} 1$, ada perbedaan signifikan antar metode. Namun pada interaksi tingkatan dan metode tidak terdapat perbedaan signifikan karena nilai $\mathrm{F}$ hitung sebesar $3,163<\mathrm{F}$ tabel $\alpha=0,05 \mathrm{df}=2,54=3,17$. Perlu dilakukan uji Post Hoc untuk mengetahui pengaruh signifikansi antar tingkatan. Berikut adalah gambar uji Post Hoc untuk tingkatan APR:

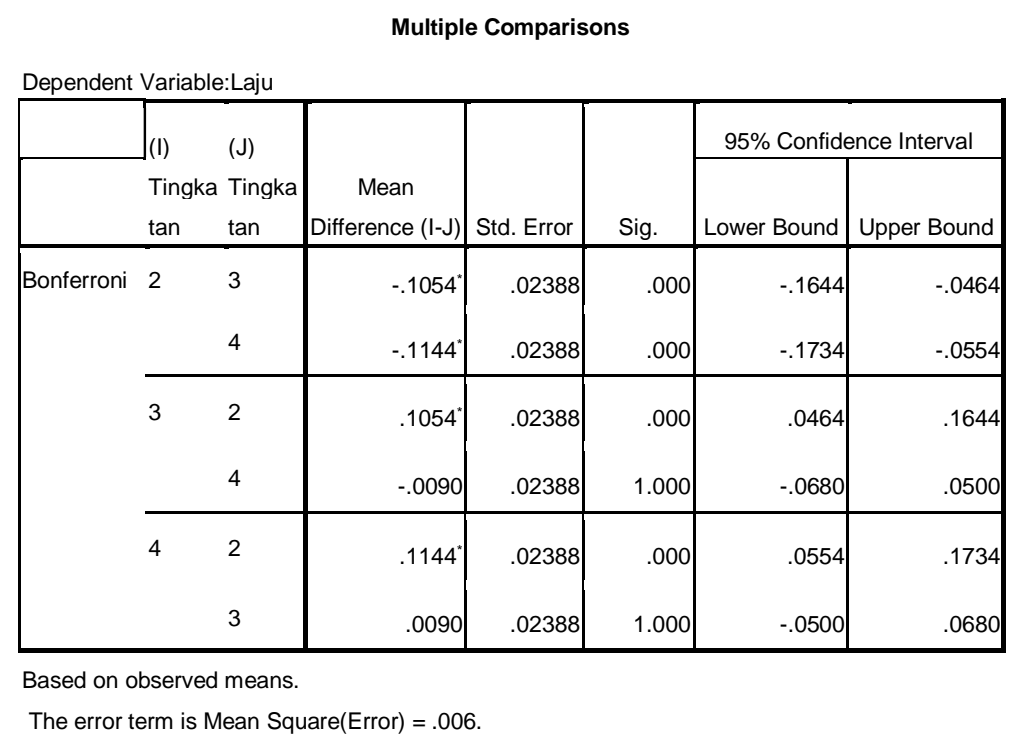

Gambar 9. Uji Post Hoc tingkatan pada APR

Pada gambar 9 diperoleh nilai Sig. sebesar 0,00 pada tingkatan 2 terhadap tingkatan 3 dan 4 sehingga dapat disimpulkan bahwa terdapat pengaruh yang signifikan. Sedangkan pada tingkatan 3 dan 4 diperoleh nilai Sig. sebesar 1,00 yang berarti bahwa tidak terdapat perbedaan yang signifikan antar tingkat 3 dan 4 . Tingkat 3 dan 4 memiliki perbedaan signifikan terhadap tingkat 2 karena nilai Sig. sebesar 0,00.

Berdasarkan grafik pertumbuhan karang transplan didapatkan hasil bahwa pertumbuhan terjadi berkisar antara 1,05-1,65 cm. Pertumbuhan panjang fragmen Acropora aspera paling besar didapat pada tingkat 4 dengan metode transplan vertikal yaitu mencapai $1,65 \mathrm{~cm}$. Sedangkan pertumbuhan panjang fragmen Acropora aspera paling rendah diperoleh pada tingkat 2 dengan metode transplan horizontal dengan panjang pertumbuhan mencapai $1,05 \mathrm{~cm}$ selama 4 bulan. Rendahnya pertumbuhan panjang pada tingkat 2 diduga karena posisinya yang sangat dekat dengan sedimen yang berada di lokasi penelitian. Tertutupnya polip oleh sedimen akan mengganggu proses penangkapan makanan (Suharsono, 2008). Pengaruh tidak langsung yang ditimbulkan, yaitu mengurangi penetrasi cahaya matahari, sehingga proses fotosintesis akan terganggu dan banyak energi yang dialokasikan karang untuk membersihkan sedimen (Supriharyono, 2000).

Rata-rata pertumbuhan panjang mutlak Acropora aspera pada penelitian yang telah dilakukan di Pulau Panjang, Jepara ini lebih rendah jika dibandingkan dengan penelitian Khalik (2009) yang dilakukan di Pulau Lompo, Makassar dengan mendapatkan rata-rata pertumbuhan panjang mencapai 1,5 - 2,47 cm dengan waktu pengamatan 3 bulan. Hal ini dapat disebabkan karena perbedaan lokasi dan kondisi perairan antar penelitian yang dilakukan.

Laju pertumbuhan dinyatakan sebagai pertambahan biomassa biota per satuan waktu (Effendie, 1997). Laju pertumbuhan karang dapat diukur dengan berbagai cara seperti pengukuran pertambahan panjang linier, area, volume, atau berat kerangka kalsiumnya dan dengan metode 
restropektif. Pertumbuhan panjang sangat bervariasi sesuai dengan metode tngkat dan kondisi lingkungan perairan. Laju pertumbuhan paling besar diperoleh pada tingkat 4 dengan metode transplan secara vertikal yaitu dengan laju pertumbuhan sebesar $0,4125 \mathrm{~cm} /$ bulan. Sedangkan paling rendah diperoleh pada tingkat 2 dengan metode transplan secara horizontal dengan laju pertumbuhan sebesar $0,22 \mathrm{~cm} / \mathrm{bulan}$.

Hal ini dikarenakan tingkat 4 terletak lebih dekat dengan permukaan air laut sehingga karang transplan memiliki peluang yang lebih besar untuk menerima cahaya matahari yang dapat membantu zooxanthellae dalam proses fotosintesanya. Pendapat ini juga diperkuat oleh Veron (1986) bahwa cahaya adalah salah satu faktor penting untuk pertumbuhan karang karena $90 \%$ makanannya dihasilkan oleh zooxanthellae yang membutuhkan cahaya untuk kelangsungan hidupnya dalam melakukan proses fotosintesis. Oleh karena itu, penentuan kedalaman optimal dapat dilihat dari laju pertumbuhan dan tingkat kelangsungan hidup karang. Kondisi lingkungan seperti sedimentasi, predasi, dan kompetisi turut mempengaruhi pertumbuhan fragmen yang dibudidayakan. Diketahui kondisi sekitar fragmen yang memiliki sedimentasi cukup tinggi sehingga memberi pengaruh terhadap pertumbuhan fragmen. Menurut Timotius (2003) pertumbuhan karang dipengaruhi oleh faktor abiotik dan biotik. Faktor abiotik dapat berupa intensitas cahaya, lama penyinaran, suhu, nutrisi, dan sedimentasi.

Laju pertumbuhan karang dengan metode transplan secara vertikal diperoleh hasil yang lebih positif dibandingkan dengan metode transplan secara horizontal dengan rata-rata laju pertumbuhan pada metode transplan secara vertikal sebesar $0,35 \mathrm{~cm} / \mathrm{bulan}$, sedangkan pada metode secara horizontal adalah sebesar $0,24 \mathrm{~cm} /$ bulan. Hal ini terjadi karena pertumbuhan Acropora yang memang cenderung vertikal (Yunus et al., 2013). Faktor lingkungan yang mendukung juga akan mempengaruhi laju pertumbuhan karang Acropora. Selain itu, karang yang ditransplantasi juga berasal dari lokasi yang sama membuat pertumbuhan menjadi lebih optimal (Hermanto, 2015).

Suhu perairan pada lokasi penelitian selama pengamatan mempunyai rata - rata $30,7^{\circ} \mathrm{C}$. Suhu perairan untuk pertumbuhan karang yang optimal berkisar antara $25-29^{\circ} \mathrm{C}$ (Dahuri, 2003). Sedangkan menurut Supriharyono (2000), batas minimun dan maksimum suhu untuk pertumbuhan karang berkisar antara $16-17^{\circ} \mathrm{C}$ dan $36^{\circ} \mathrm{C}$. sehingga suhu $30,7^{\circ} \mathrm{C}$ pada lokasi penelitian masih dapat ditolerir. Suhu mempengaruhi kecepatan metabolisme, reproduksi, dan perombakan bentuk luar dari karang (Sadarun et al., 2006). Suhu yang relatif konstan sangat baik untuk pertumbuhan biota karang, sebaliknya perubahan suhu secara tiba-tiba dapat menyebabkan stres pada karang yang dapat berdampak kematian.

Salinitas perairan pada lokasi penelitian rata - rata adalah sebesar $30,8 \% 0$. Salinitas tersebut tergolong sesuai untuk pertumbuhan karang karena menurut Dahuri (2003), salinitas untuk pertumbuhan karang yang optimal adalah sebesar $30-35 \% 0$.. Menurut Hermanto (2015), pertumbuhan karang dengan salinitas yang ekstrim dapat mengurangi laju pertumbuhan karang. Penurunan laju pertumbuhan bergantung juga pada daya toleransi karang terhadap perubahan salinitas.

Lokasi penelitian mempunyai derajat keasaman $(\mathrm{pH})$ rata - rata sebesar 8,5-8,6. Menurut Tomascik (1997), habitat yang cocok bagi pertumbuhan karang adalah pH dengan nilai 8,2 - 8,5. Sehingga lokasi penelitian masih berada pada batas kewajaran derajat keasaman yang optimal. Daya tahan terumbu karang terhadap salinitas memiliki ambang batas dan tidak sama pada setiap jenisnya (Liliek dan Hartoni, 2012).

Laju sedimentasi pada lokasi penelitian mencapai kisaran 30,62 - 40,7 g/m2/hari. Perairan yang memiliki laju kecepatan penumpukan sedimen yang tinggi akan sulit untuk menjadi tempat yang baik bagi pertumbuhan karang. Laju sedimentasi yang tinggi akan menyebabkan penetrasi cahaya di air laut akan berkurang dan hewan karang akan bekerja keras untuk membersihkan partikel yang menutupi tubuhnya. Selain itu pengadukan dari partikel sedimen juga berpengaruh terhadap kecerahan perairan yang dapat menghambat masuknya sinar matahari. Sinar matahari dibutuhkan zooxanthellae untuk melakukan proses fotosintesis. Karang memiliki berbagai macam cara untuk melepaskan sedimen yang menempel pada tubuhnya yaitu dengan cara: melepaskan sedimen yang menempel secara pasif, perbesaran polip melalui sirkulasi air, pergerakan jaringan tentacular, melalui gerak silia, dan memproduksi cairan mocus. 


\section{KESIMPULAN}

Berdasarkan hasil penelitian yang telah dilakukan didapatkan hasil dari perbandingan kedua metode yang diaplikasikan. Hasil yang didapatkan terjadi laju pertumbuhan yang lebih tinggi pada metode transplan vertikal sebesar $0,35 \mathrm{~cm} /$ bulan sedangkan metode transplan horizontal hanya sebesar $0,26 \mathrm{~cm} /$ bulan. Didapatkan hasil penelitian bahwa semakin tinggi tingkat yang digunakan maka semakin tinggi laju pertumbuhan fragmen karang. Laju pertumbuhan tertinggi terjadi pada tingkat 4 dengan laju pertumbuhan sebesar $0,4125 \mathrm{~cm} /$ bulan dan terndah terjadi pada tingkat 2 sebesar $0,22 \mathrm{~cm} / \mathrm{bulan}$. Pengaruh perbedaan metode dan tingkat transplantasi pada karang menunjukkan hasil bahwa pada metode terdapat pengaruh yang signifikan karena hasil yang didapatkan Sig. $=0,00$ begitu juga dengan tingkatan.

\section{DAFTAR PUSTAKA}

Dahuri, R. 2003. Keanekaragaman Hayati Laut : Aset Pembangunan Berkelanjutan Indonesia. Gramedia Pustaka Utama. Jakarta.

Edwards, A.J \& Gomez, E.D. 2008. Konsep dan Panduan Restorasi Terumbu : Membuat Pilihan Bijak di Antara Ketidakpastian. Terj. Dari Reef Restoration Concepts and Guidelines : Making Sensible Management Choices In The Face Of Uncertainty. Oleh : Yusri. S., Estradivari, N.S. Wijoyo, Indris. Yayasan Terumbu Karang Indonesia. Jakarta.

Effendie, M.I. 1979. Metode Biologi Perikanan. Cetakan Pertama. Yayasan Dewi Sri, Bogor.

Hermanto, B. 2015. Pertumbuhan Fragmen Acropora formosa pada Ukuran yang Berbeda dengan Metode Transplantasi di Perairan Selat Lembeh. LIPI. Bitung, Sulawesi Utara

Khalik, I. 2009. Laju Pertumbuhan dan Sintasan Karang Bercabang Acroporidae Yang Ditransplantasi Pada Substrat Alami (Massive Dead Corals) Di Perairan Pulau Barrang Lompo, Makassar. Skripsi. Jurusan IImu Kelautan Fakultas Ilmu Kelautan dan Perikanan Universitas Hasanuddin, Makassar.

Liliek, E. \& Hartoni. 2012. Kondisi Tutupan Terumbu Karang Keras dan Karang Lunak di Pulau Pramuka Kabupaten Administratif Kepulauan Seribu DKI Jakarta. Maspari Journal. 5(2):111118.

Lirman D, Young-Lahiff, C. \& Schopmeyer, S,. 2012. A Review of Reef Restoration and Coral Propagation Using The Threatened Genus Acroproa in The Caribbean and Western Atlantic. Bulletin of Marine Science. 88(4):1075-1098.

Munasik, Sugianto, D.N. \& Sabdono, A. 2017. Reef Development on Artificial Patch Reefs in Shallow Water of Panjang Island, Central Java. 3rd International Conference on Tropical and Coastal Region. Eco Development. IOP Publishing.

Nazir. 1988. Metodologi Penelitian. Jakarta: Ghalia Indonesia.

Pardede, M.F. 2012. Efektivitas Terumbu Buatan Berbahan Dasar Tempurung Kelapa sebagai Fish Aggregating Device di Pulau Pramuka Kepulauan Seribu. Skripsi. IPB. Bogor.

Sadarun, Nezon E, Wardono S, Fandy Y A, Nuriadi L. 2006. Pedoman Pelaksanaan Transplantasi Karang. Departemen Kelautan dan Perikanan. Jakarta.

Soedharma, D. \& Arafat, D. 2005. Perkembangan Transplantasi Karang di Indonesia. Soedharma D, M. F. Rahardjo, Ferinaldy, Sri Eko Susilawati, Dondy Arafat (Ed). Prosiding Seminar Transplantasi. Bogor, 8 September 2005. Pusat Penelitian Lingkungan Hidup - Lembaga Penelitian dan Pengabdian Masyarakat - IPB.

Suharsono, 2008. Jenis-Jenis Karang Di Indonesia. LIPI. Jakarta.

Supriharyono. 2000. Pengelolaan Ekosistem Terumbu Karang. Penerbit Djambatan. Jakarta.

Supriharyono. 2007. Konservasi Ekosistem Sumber Daya Hayati di Wilayah Pesisir dan Laut Tropis. Yogyakarta: Pustaka Pelajar.

Timotius, S. 2003. Biologi Terumbu Karang. Makalah Training Course. Yayasan Terangi. Veron, J.E.N. 2000. Coral of The World . Australian Institute of Marine Science. Townsville. Yunus, B,H. Wijayanti, D.P., Sabdono, A. 2013. Transplantasi Karang Acropora Aspera Dengan Metode Tali Di Perairan Teluk Awur, Jepara. Buletin Oseanografi Marina. 2(3):22-28 